\title{
Effects of Heat Removal Through the Hand on Metabolism and Performance During Cycling Exercise in the Heat
}

\author{
Andrew R. Hsu, Todd A. Hagobian, Kevin A. Jacobs, Hamdee Attallah, \\ and Anne L. Friedlander
}

\section{Catalogue Data}

Hsu, A.R.; Hagobian, T.A.; Jacobs, K.A.; Attallah, H.; and Friedlander, A.L. (2005). Effects of heat removal through the hand on metabolism and performance during cycling exercise in the heat. Can. J. Appl. Physiol. 30(1): 87-104. () 2005 Canadian Society for Exercise Physiology.

Key words: core temperature, hyperthermia, thermoregulation, hand-cooling Mots-clés: température corporelle, hyperthermie, thermorégulation, refroidissement de la main

\begin{abstract}
Résumé
Objective: This two-part study tested the hypotheses that the use of a new cooling device, purported to extract heat from the body core through the palm of the hand, would (a) attenuate core temperature rise during submaximal exercise in the heat, thereby suppressing exercise-associated metabolic changes, and (b) facilitate a higher sustained workload, thus shortening the completion time of a time-trial performance test. Methods: In Study 1, 8 male triathletes (age $27.9 \pm 2.0 \mathrm{yrs}$, mass $77.2 \pm 3.1 \mathrm{~kg}$, $\dot{V O}{ }_{2}$ peak $59.0 \pm 4.1 \mathrm{ml} \cdot \mathrm{min}^{-1} \cdot \mathrm{kg}^{-1}$ ) cycled for $1 \mathrm{hr}$ at the same absolute workload ( 60\% Vं ${ }_{2}$ peak) in a heated room (31.9 \pm 0.1 ${ }^{\circ} \mathrm{C}, 24 \pm 1 \%$ humidity) on two occasions counterbalanced for cooling $(C)$ or noncooling (NC). In Study 2, 8 similar subjects (age $26.9 \pm 2.0$ yrs, mass $75.2 \pm 3.7 \mathrm{~kg}$, $\dot{V O}_{2}$ peak $54.1 \pm 3.1$ $\left.\mathrm{ml} \cdot \mathrm{min}^{-1} \cdot \mathrm{kg}^{-1}\right)$ performed two $30-\mathrm{km}$ cycling time-trial performance tests under the same conditions $\left(C_{T}, N C_{T}\right)$. Results: In Study 1, cooling attenuated the rise in tympanic temperature $\left(T_{T Y}\right)\left(1.2 \pm 0.2 \mathrm{vs} .1 .8 \pm 0.2{ }^{\circ} \mathrm{C} ; p<0.01\right)$ and lowered mean oxygen consumption $\left(\dot{V} \mathrm{O}_{2}, 2.4 \pm 0.1\right.$ vs. $\left.2.7 \pm 0.1 \mathrm{~L} \cdot \mathrm{min}^{-1} ; p<0.05\right)$ and blood lactate $(1.7 \pm 0.2$ vs. $2.2 \pm 0.2$ $\left.\mathrm{mmol} \cdot \mathrm{L}^{-1} ; \mathrm{p}<0.01\right)$ during exercise. There were no significant differences in respiratory
\end{abstract}

The authors are with the Clinical Studies Unit, Bldg MB2, Veterans Affairs Palo Alto Health Care System, Palo Alto, CA 94304, USA. 
exchange ratio (RER), blood glucose, heart rate $(H R)$, face temperature $\left(T_{F}\right)$, or back temperature $\left(T_{B}\right)$ between $N C$ and $C$. In Study 2, time to complete $30 \mathrm{~km}$ was $6 \pm 1 \%$ less with cooling than without cooling (60.9 \pm 2.0 vs. $64.9 \pm 2.6 \mathrm{~min} ; p<0.01)$. During the last $20 \%$ of $C_{T}$, subjects sustained a workload that was $14 \pm 5 \%(p=0.06)$ higher than $N C_{T}$ at the same $T_{T Y}$ and HR. Conclusions: Heat extraction through the hand during cycle ergometer exercise in the heat can (a) lower $T_{T Y}$, lactate concentration, and $\dot{V} \mathrm{O}_{2}$ during a submaximal set-workload test and $(b)$ reduce the time it takes to complete a 30-km time-trial test.

But: Cette étude se divise en deux parties et porte sur un nouveau dispositif de refroidissement conçu pour extraire par la paume de la main la chaleur du noyau de l'organisme. L'étude teste que le dispositif: (a) atténue l'augmentation de la chaleur corporelle au cours d'un exercice par temps chaud et par conséquent, stoppe les modifications du métabolisme associées à l'exercice, et (b) favorise une plus grande charge de travail, ce qui abrège le temps de performance dans une course contre la montre. Méthode: Dans la première étude, 8 triathloniens (sexe masculin, âge 27,9 $\pm 2,0$ ans; masse 77,2 $\pm 3,1 \mathrm{~kg} ; \dot{V} \mathrm{O}_{2}$ de crête $59,0 \pm$ $\left.4,1 \mathrm{ml} \cdot \mathrm{min}^{-1} \cdot \mathrm{kg}^{-1}\right)$ pédalent durant $1 \mathrm{~h}$ à une intensité de travail donnée ( $\sim 60 \% \dot{\mathrm{VO}} \mathrm{O}_{2}$ max de crête) dans un local chauffé $\left(31,9 \pm 0,1{ }^{\circ} \mathrm{C}, 24 \pm 1 \%\right.$ d'humidité), et ce, en deux moments contrebalancés: avec refroidissement $(C)$ et sans refroidissement $(N C)$. Dans la deuxième étude, 8 sujets semblables (sexe masculin, âge 26,9 $\pm 2,0$ ans; masse 75,2 $\pm 3,7 \mathrm{~kg} ; \dot{\mathrm{VO}}{ }_{2}$ de crête $\left.54,1 \pm 3,1 \mathrm{ml} \cdot \mathrm{min}^{-1} \cdot \mathrm{kg}^{-1}\right)$ participent à deux courses de 30 -km contre la montre dans les mêmes conditions $\left(C_{T} N C_{T}\right)$. Résultats: Dans la première étude, le refroidissement atténue l'augmentation de la température tympanique $\left(T_{T Y}\right)(1,2 \pm 0,2$ comparativement à $1,8 \pm 0,2$ $\left.{ }^{\circ} \mathrm{C} ; \mathrm{p}<0,01\right)$ et abaisse la consommation d'oxygène $\left(\dot{V}_{2}: 2,4 \pm 0,1\right.$ comparativement à 2,7 $\left.\pm 0,1 \mathrm{~L} \cdot \mathrm{min}^{-1} ; p<0,05\right)$ et la concentration de lactate $(1,7 \pm 0,2$ comparativement à $2.2 \pm$ $\left.0.2 \mathrm{mmol} \cdot \mathrm{L}^{-1} ; p<0,01\right)$ à l'effort. Le ratio d'échanges gazeux (RER), le glucose sanguin, la fréquence cardiaque $(H R)$, la température du visage $\left(T_{F}\right)$, et du dos $\left(T_{B}\right)$ ne varient pas significativement d'une condition $(C)$ à l'autre $(N C)$. Dans la deuxième étude, le temps de performance sur $30-\mathrm{km}$ est écourté de $6 \pm 1 \%$ par le refroidissement $(60,9 \pm 2,0$ comparativement à 64,9 $\pm 2,6 \mathrm{~min} ; p<0,01)$. De plus, durant le dernier cinquième du $C_{T}$, les sujets maintiennent une plus grande charge de travail $(14 \pm 5 \%, p=0,06)$ que dans la condition $\mathrm{NC}_{T}$ pour une même $T_{T Y}$ et une même HR. Conclusion: l'extraction de la chaleur corporelle au niveau de la main au cours d'un exercice sur ergocycle a pour effet: (a) d'abaisser la $T_{T Y}$, la concentration de lactate, et le $\dot{V} \mathrm{O}_{2}$ au cours d'un test d'effort sousmaximal et (b) de réduire le temps de performance dans une course de $30 \mathrm{~km}$ contre la montre.

\section{Introduction}

Endurance capacity is impaired in hot compared with cool or neutral ambient conditions (Febbraio, 1999a; Nielsen et al., 1993). The buildup of internal heat loads which can limit physical performance and time to exhaustion is affected by preexercise body temperatures (Booth et al., 1997; Gonzalez-Alonso et al., 1999; Lee and Haymes, 1995). Preexercise cooling techniques designed to increase heat storage capacity (e.g., cold air exposure and water immersion) have been shown to provide moderate performance benefits (Booth et al., 1997; Hessemer et al., 1984; Olschewski and Bruck, 1988; Schmidt and Bruck, 1981). For example, Hessemer et al. (1984) showed that a reduction in preexercise core temperature using cold air exposure resulted in a subject-selected $6.8 \%$ increase in absolute workload com- 
pared to noncooled trials during 1 hour of cycle ergometer exercise. Similarly, whole body cooling via water immersion has also been shown to reduce core temperature and improve cycle ergometer endurance performance (Bolster et al., 1999; Booth et al., 1997; Gonzalez-Alonso et al., 1999). However, the performance benefits of preexercise cooling are transient and typically decrease after 20-25 minutes of exercise (Bolster et al., 1999; Booth et al., 1997).

A new cooling device (Rapid Thermal eXchange, AVAcore Inc., Ann Arbor, MI) utilizes the heat exchange vascular structures (arterial venous anastamoses and associated venous plexuses) underlying the nonhairy skin surfaces in the palms of the hands to directly manipulate core temperature. This technique has been reported to be effective for delivering heat to the core of cold-stressed vasoconstricted individuals (Grahn et al., 1998). In addition, the device, adapted for use on the anastamoses in the soles of the feet, has been shown to attenuate the rise in tympanic temperature in individuals with spinal cord injury during arm-cranking exercise in the heat (Hagobian et al., 2004). Whether the new hand-cooling device can provide a benefit to trained athletes during cycling exercise has yet to be reported. Previous studies show that immersion of the hands in cold water following exercise in the heat can accelerate the fall in core temperature in fit young men. Therefore, hand-cooling may be an effective way to lower core temperature during exercise in athletes experiencing heat stress (House et al., 1997; Livingstone et al., 1989).

We hypothesized that use of the cooling device would attenuate the rise in core temperature during submaximal exercise in the heat, and thereby reduce exercise-induced changes in metabolic variables such as oxygen consumption $\left(\dot{\mathrm{VO}}_{2}\right)$, heart rate (HR), respiratory exchange ratio (RER), and lactate accumulation. We also hypothesized that cooling would allow a greater sustained workload during a time-trial cycling test, thus reducing the time to complete the distance. In total, this study was designed to gather preliminary data on the efficacy of the hand-cooling device and elucidate potential underlying mechanisms by which this cooling technique might improve endurance cycling performance.

\section{Methods}

\section{SUBJECTS}

Two groups of 8 healthy, nonsmoking, trained male triathletes, ages 18-35, were recruited from Stanford University and surrounding communities by word of mouth. Individuals with previous histories or symptoms of heart disease, hypertension, or physical conditions that might limit activity were excluded. A maximum oxygen consumption level ( $\dot{\mathrm{VO}}_{2}$ peak) $>45 \mathrm{ml} \cdot \mathrm{min}^{-1} \cdot \mathrm{kg}^{-1}$ was required for participation to ensure that subjects would be able to perform the exercise tests under stressful environmental conditions. Group 1 (age $27.9 \pm 2.0 \mathrm{yrs}$, mass $77.2 \pm 3.1 \mathrm{~kg}, \dot{\mathrm{VO}}_{2}$ peak $59.0 \pm 4.1 \mathrm{ml} \cdot \mathrm{min}^{-1} \cdot \mathrm{kg}^{-1}$ ) was recruited for the fixed-workload protocol (Study 1), while Group 2 (age $26.9 \pm 2.0$ yrs, mass $75.2 \pm 3.7 \mathrm{~kg}, \dot{\mathrm{V} O}{ }_{2}$ peak $54.1 \pm 3.1$ $\mathrm{ml} \cdot \mathrm{min}^{-1} \cdot \mathrm{kg}^{-1}$ ) underwent the $30-\mathrm{km}$ time-trial performance tests (Study 2). The Stanford University Administrative Panel on Human Subjects in Medical Research approved both protocols, and written informed consent was obtained from all subjects. 


\section{SCREENING TESTS}

Prior to participating in any physical activity, subjects underwent a screening appointment that included a health history, physical exam, and electrocardiogram (ECG) at the Clinical Studies Unit (CSU) of the Veterans Affairs Palo Alto Health Care System. Following medical clearance, peak oxygen consumption ( $\dot{\mathrm{VO}}_{2}$ peak) was assessed in a continuous progressive exercise test to volitional exhaustion on an electrically braked cycle ergometer (SensorMedics 800, VIASYS Healthcare, Yorba Linda, CA). After a 2-min rest period, subjects began cycling at $50 \mathrm{~W}$ and the workload was increased by $50-\mathrm{W}$ increments every 2 min until $150 \mathrm{~W}$, after which point the workload was increased by $30-\mathrm{W}$ increments until subjects became exhausted and voluntarily stopped exercising. Expired respiratory gases were collected continuously and analyzed using an online system (Parvomedics Truemax 2400, Consentius Technologies, Sandy, UT). The recorded $\dot{\mathrm{VO}}_{2}$ peak was the highest $\dot{\mathrm{VO}}_{2}$ value that was sustained for $30 \mathrm{~s}$ during the test. Heart rate was recorded every other minute throughout the test using a Polar heart rate monitor (Woodbury, $\mathrm{NY}$ ). An individual experienced in performing $\mathrm{V}_{2}$ peak tests, trained in pulmonary resuscitation, and trained to recognize the termination criteria outlined by the American College of Sports Medicine was present during all tests.

\section{FIXED-WORKLOAD TESTING PROTOCOL (STUDY 1)}

Each subject in Study 1 completed two fixed-workload tests in the heat at $\sim 60 \%$ $\dot{\mathrm{V}} \mathrm{O}_{2}$ peak a week apart with the cooling device either activated (C) or not (NC). Subjects were randomly assigned to one of two counterbalanced testing orders. They arrived at the CSU fully hydrated, having already consumed at least $500 \mathrm{ml}$ of water. Hydration status was estimated using preexercise starting body mass. For $24 \mathrm{hrs}$ prior to testing, food intake was standardized and subjects refrained from exercise. Subjects ate a small, self-selected, standardized meal which simulated their precompetition food intake ( $575 \mathrm{kcal}, 80 \% \mathrm{CHO}, 5 \%$ fat, $15 \%$ protein) $3 \mathrm{hrs}$ prior to the start of exercise, making sure to record and replicate their food intake before both trials. A catheter (22 gauge, $3.17 \mathrm{~cm}$, Angiocath, Becton Dickinson, Franklin Lakes, NJ) was placed in a superficial left wrist vein for blood sampling during rest, exercise, and recovery so that blood lactate and glucose concentrations could be analyzed. Subjects then drank $250 \mathrm{ml}$ of water and sat for $1 \mathrm{hr}$ in a heated room $\left(31.9 \pm 0.1^{\circ} \mathrm{C}, 24 \pm 1 \%\right.$ humidity $)$ prior to exercise to acclimate to the heat and prevent any rapid shifts in body temperature due to transient vasodilation or vasoconstriction associated with being transferred between different environmental temperatures (unpublished observations).

Room temperature and humidity were recorded every $5 \mathrm{~min}$ and there were no differences in room temperature or humidity between trials. The device was not used during the $1 \mathrm{hr}$ of rest, and no fans or external airflow were permitted before or during the tests. Subjects sat on an electrically braked cycle ergometer $15 \mathrm{~min}$ before exercise, and appropriate thermocouple temperature probes (Mon-a-therm, Mallinckrodt Medical Inc., St. Louis, MO) were placed in the left ear (touching the tympanic membrane), on the left upper maxilla (face), and on the upper thoracic spine (back). To ensure that tympanic temperature was measured, subjects inserted the probe in their ear as far as possible until contact was made with the 
tympanic membrane. A small cotton ball attached to the end of the probe ensured that there was no external heat input from the environment. Ongoing work in our lab using similar subjects $\left(n=16\right.$, age $26.0 \pm 1.3$ yrs, mass $83.5 \pm 4.0 \mathrm{~kg}, \dot{\mathrm{V}} \mathrm{O}_{2}$ peak $\left.46.7 \pm 1.6 \mathrm{ml} \cdot \mathrm{min}^{-1} \cdot \mathrm{kg}^{-1}\right)$ and an identical exercise protocol has shown a strong correlation between $\mathrm{T}_{\mathrm{TY}}$ and esophageal temperature $\left(\mathrm{T}_{\mathrm{esoph}}\right)(r=0.99)$, with $\mathrm{T}_{\mathrm{TY}}$ consistently lower by $\sim 0.5^{\circ} \mathrm{C}$. Probes were secured to skin using breathable porous tape (Transpore surgical tape, 3M Healthcare, St. Paul, MN). A Polar heart rate monitor was placed across the chest.

A noseclip and mouthpiece were fitted to subjects and connected to a metabolic cart via standard wide bore tubing $10 \mathrm{~min}$ before exercise. A 5-min baseline calorimetry sample was taken along with a baseline blood sample. For each blood measurement, a 3-ml waste sample was taken followed by $3 \mathrm{ml}$ for the measurement of glucose and lactate using a portable glucose analyzer (Accu-chek Advantage, Roche Diagnostics, Berkeley, CA) and lactate analyzer (Yellow Springs Instruments, 1500 sports lactate analyzer, Yellow Springs, OH), respectively. After each blood draw, the catheter was flushed with $2 \mathrm{ml}$ of saline to prevent coagulation within the catheter. Five minutes before exercise, subjects placed their right hand in the cooling device, which rested on the cycle handlebars, and it was then activated (C) or not activated (NC). For the NC tests, the wrist seal of the device was left open in order to prevent artificial heat insulation of the hand. After the baseline period, subjects cycled for $1 \mathrm{hr}$ at a workload that elicited $\sim 60 \% \mathrm{VO}_{2}$ peak while continuously being cooled or noncooled. The workload was adjusted during the first $10 \mathrm{~min}$ of exercise (and when needed, small adjustments were made during the 30 -min measurement point) based on $\dot{\mathrm{VO}}_{2}$ values $\left(\mathrm{L} \cdot \mathrm{min}^{-1}\right)$ to maintain $60 \% \mathrm{VO}_{2}$ peak as closely as possible. After the 30-min mark, workloads were left constant for the duration of exercise. The second test was performed using the same absolute workloads as in the first test for the entire duration of exercise.

Tympanic, face, and back temperatures were recorded every second on a data logger (Omega Inc. OM-3000, Stamford, CT) and converted into 5-min averages. Oxygen consumption $\left(\mathrm{V}_{2}\right)$, respiratory exchange ratio (RER), blood lactate concentration, and blood glucose levels were measured every $15 \mathrm{~min}$, and heart rate was recorded every $5 \mathrm{~min}$. Subjects drank $250 \mathrm{ml}$ of water at 20, 40, and 60 min of exercise. Upon completing the exercise, they stopped cycling, remained in the heated room, and sat quietly in a chair for $30 \mathrm{~min}$ with their right hand still in the device while measurements were being taken at the time intervals described above. Water losses were estimated from differences in body mass measured before the $1 \mathrm{hr}$ of rest and after recovery, taking into account the ingestion of water and assuming the specific gravity of water and sweat to be 1.0 and 1.002 , respectively (Mao et al., 2001). Subjects wore the same athletic clothing (t-shirts and shorts) during rest, exercise, and recovery for both trials. Body mass was standardized before and after exercise by weighing subjects in shorts with skin toweled dry and no urination or defecation between measurements.

\section{TIME-TRIAL TESTING PROTOCOL (STUDY 2)}

Each subject in Study 2 completed two 30-km time-trial tests in the heat a week apart with the cooling device either activated $\left(\mathrm{C}_{\mathrm{T}}\right)$ or not $\left(\mathrm{NC}_{\mathrm{T}}\right)$ in random order. As in Study 1, subjects arrived at the CSU fully hydrated, having already con- 
sumed $500 \mathrm{ml}$ of water and after standardizing food intake, sleep, and avoiding exercise for the previous $24 \mathrm{hrs}$. They ate a small standardized meal similar to their precompetition food intake (460 kcal, $50 \% \mathrm{CHO}, 30 \%$ fat, $20 \%$ protein), drank $250 \mathrm{ml}$ of water, and rested for $1 \mathrm{hr}$ in a heated room $\left(32.3 \pm 0.1{ }^{\circ} \mathrm{C}, 22 \pm 2 \%\right.$ humidity). As in Study 1, the 1-hr rest period was designed to stabilize starting baseline temperatures between trials. There were no differences in room temperature or humidity between trials, and no fans were used. During the rest period of each trial, subjects' personal bicycle frames were connected to a stationary cycling trainer (Computrainer 2000, Seattle, WA) and the trainer was appropriately calibrated following the manufacturer's guidelines. Temperature probes and a heart rate monitor were connected to subjects 15 min before exercise as in Study 1. Subjects placed their left hand in the cooling device, which rested on the cycle handlebars, 5 min before exercise and it was then activated $\left(\mathrm{C}_{\mathrm{T}}\right)$ or not activated $\left(\mathrm{NC}_{\mathrm{T}}\right)$. The wrist seal of the device was left open during $\mathrm{NC}_{\mathrm{T}}$ trials as in Study 1 so the temperature in the device could equilibrate with the environmental temperature.

After a 5-min warm-up at $0 \mathrm{~W}$, subjects performed a 30-km time-trial. Temperature and heart rate were recorded as in Study 1, and subjects drank $250 \mathrm{ml}$ of water at 10 and $20 \mathrm{~km}$. During rest and exercise for both trials, subjects wore the same athletic clothing (t-shirts and shorts). They were deprived of all time references during the time trials including elapsed time and cycling speed. Subjects completed the $30-\mathrm{km}$ distance as quickly as possible and were only able to monitor distance completed during the trials. Upon completion of exercise, time to completion was recorded and subjects were taken off the trainer and the cooling device. Although no familiarization time trial was performed by subjects specifically for the study, all were accustomed to similar testing procedures and performed time trials as part of their team training. The coefficient of variation for this type of cycling time-trial testing in our lab is $2.7 \%$.

\section{HAND-COOLING DEVICE}

The hand-cooling device (AVAcore Inc., Palo Alto, CA) utilizes the combined application of negative pressure and a heat sink to the nonhairy skin surface of the hand to increase heat exchange between the circulating blood and the external environment. The negative pressure distends the subcutaneous venous plexuses to maximize local blood volume, while the cold sink extracts heat out of the circulating blood. The cooled blood is delivered directly to the body core via venous return. The device consists of a metallic heat-exchanging surface on which the palm rests surrounded by a clear plastic chamber (Figure 1). A neoprene seal connected to the chamber above the wrist allows for a vacuum seal. Air is pumped from the device to create a negative pressure while cooled water is circulated beneath the heat-exchange surface, drawing heat back to a small reservoir of cooled water. Pressure was set at $-25 \mathrm{in} \cdot \mathrm{H}_{2} \mathrm{O}^{-1}$ and water (plate) temperature at $22{ }^{\circ} \mathrm{C}$ for all tests. Previous work using the cooling device on the foot suggests that negative pressure is an important component for the overall efficacy of the device (Hagobian et al., 2004). Suction was turned off and subjects removed their hand for approximately 30 s every 10 min during all tests to reduce blood pooling. For the noncooling trials, subjects placed their hand in the device but neither the vacuum nor the water circulating pumps were activated. 


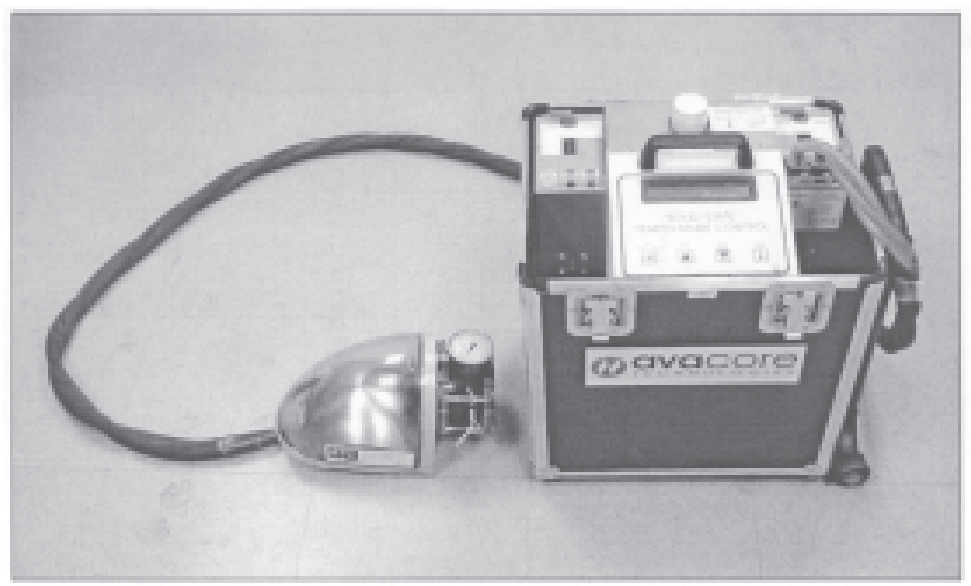

Figure 1. The hand-cooling device, consisting of a water cooling bath and an adapted peripheral hand unit.

\section{STATISTICS}

Statistics were performed with StatView software (SAS Institute, Cary, NC), and data were analyzed using two-way ANOVA tests (test $\times$ time) with repeated measures for time series analyses. When appropriate, Tukey HSD post hoc significance tests were performed. Paired $t$-tests were used to evaluate peak changes in values during exercise. Statistical significance was set at $p<0.05$. All data presented are means $\pm S E M$.

\section{Results}

\section{STUDY 1 (FIXED-WORKLOAD TESTS)}

Tympanic Temperature $\left(T_{T Y}\right)$. Preexercise resting $\mathrm{T}_{\mathrm{TY}}$ (after $1 \mathrm{hr}$ of rest and prior to device activation) did not differ between trials $\left(\mathrm{NC}=36.7 \pm 0.1{ }^{\circ} \mathrm{C}\right.$; $\left.\mathrm{C}=36.6 \pm 0.1^{\circ} \mathrm{C}\right) . \mathrm{T}_{\mathrm{TY}}$ tended to be higher throughout exercise without cooling, with the largest differences in $\mathrm{T}_{\mathrm{TY}}$ occurring during the last $15 \mathrm{~min}$ of exercise (Figure 2). Without cooling, $\mathrm{T}_{\mathrm{TY}}$ increased $1.8 \pm 0.2^{\circ} \mathrm{C}$ to a peak of $38.5 \pm 0.2^{\circ} \mathrm{C}$. With cooling, $\mathrm{T}_{\mathrm{TY}}$ increased by only $1.2 \pm 0.2^{\circ} \mathrm{C}$ to a peak of $37.8 \pm 0.2{ }^{\circ} \mathrm{C}$ (Figure 2 ). Between the two trials, both the highest $\mathrm{T}_{\mathrm{TY}}$ attained and the peak rise in $\mathrm{T}_{\mathrm{TY}}$ differed significantly $(p<0.01)$, with peak rise differing by $33 \%$.

Face $\left(T_{F}\right)$ and Back $\left(T_{B}\right)$ Temperature. Cooling had no significant effect on mean $\mathrm{T}_{\mathrm{F}}$ and $\mathrm{T}_{\mathrm{B}}$ during rest, exercise, or recovery (Table 1). However, peak increases in $\mathrm{T}_{\mathrm{F}}$ during exercise were $1.4 \pm 0.3{ }^{\circ} \mathrm{C}$ and $1.1 \pm 0.4{ }^{\circ} \mathrm{C}$ above baseline for $\mathrm{NC}$ and $\mathrm{C}$, respectively. Peak exercise-induced increases in $\mathrm{T}_{\mathrm{B}}$ were similar between trials $\left(1.3 \pm 0.3^{\circ} \mathrm{C}\right.$ and $1.2 \pm 0.4^{\circ} \mathrm{C}$ for $\mathrm{NC}$ and $\mathrm{C}$, respectively).

Cardiovascular and Metabolic Responses. Oxygen consumption $\left(\mathrm{V}_{2}\right)$ during preexercise rest and postexercise recovery was not affected by cooling. 


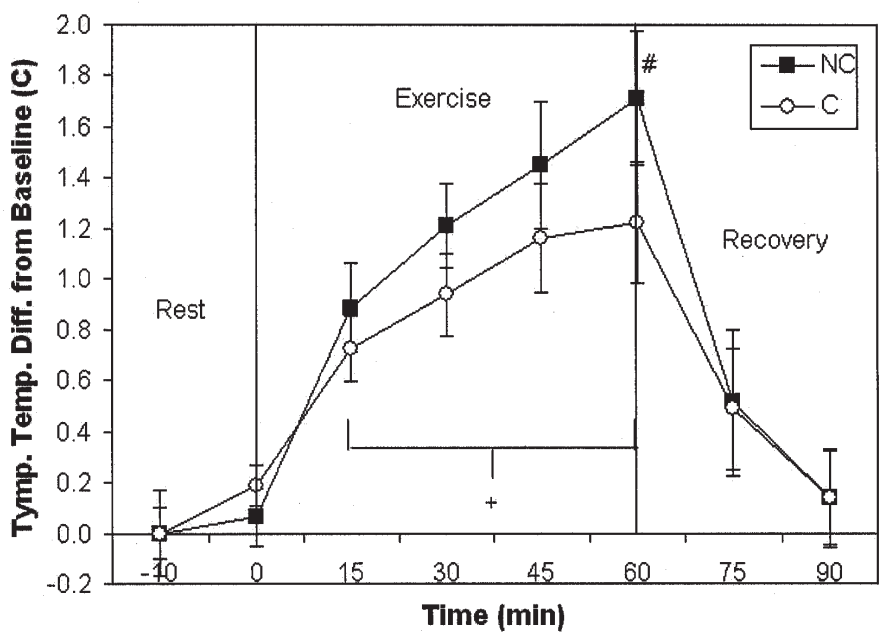

Figure 2. Tympanic temperature $\left(\mathrm{T}_{\mathrm{TY}}\right)$ difference from baseline during rest, exercise, and recovery (mean $\pm S E M$ ). "Peak increase in NC significantly different from $\mathrm{C}(p<$ $0.01),{ }^{+}$Significantly different from rest $(p<0.05)$. $\mathrm{NC}=$ noncooled; $\mathrm{C}=$ cooled.

Table 1 Mean Temperature, Cardiovascular, and Metabolic Responses for Noncooled (NC) and Cooled (C) Fixed Workload Trials (Study 1)

\begin{tabular}{lccccc} 
Variable & Trial & Baseline $^{\mathrm{a}}$ & Rest $^{\mathrm{b}}$ & Exercise & Recovery \\
\hline \multirow{2}{*}{ Face temp. $\left({ }^{\circ} \mathrm{C}\right)$} & $\mathrm{NC}$ & $35.8 \pm 0.3$ & $36.0 \pm 0.3$ & $36.7 \pm 0.3^{+}$ & $35.7 \pm 0.3$ \\
& $\mathrm{C}$ & $35.5 \pm 0.2$ & $35.8 \pm 0.1$ & $36.2 \pm 0.3^{+}$ & $35.5 \pm 0.2$ \\
Back temp. $\left({ }^{\circ} \mathrm{C}\right)$ & $\mathrm{NC}$ & $35.5 \pm 0.2$ & $35.7 \pm 0.3$ & $36.4 \pm 0.3^{+}$ & $34.4 \pm 0.4^{+}$ \\
& $\mathrm{C}$ & $35.3 \pm 0.2$ & $35.4 \pm 0.2$ & $36.0 \pm 0.4^{+}$ & $34.3 \pm 0.4^{+}$ \\
$\dot{\mathrm{VO}}_{2}\left(\mathrm{~L} \cdot \mathrm{min}^{-1}\right)$ & $\mathrm{NC}$ & $0.41 \pm 0.05$ & $0.40 \pm 0.03$ & $2.7 \pm 0.1^{*+}$ & $0.52 \pm 0.03$ \\
& $\mathrm{C}$ & $0.38 \pm 0.03$ & $0.37 \pm 0.02$ & $2.4 \pm 0.1^{+}$ & $0.50 \pm 0.04$ \\
$\mathrm{HR}\left(\right.$ beats $\left.\cdot \mathrm{min}^{-1}\right)$ & $\mathrm{NC}$ & $64 \pm 6$ & $68 \pm 6$ & $157 \pm 4^{+}$ & $87 \pm 3^{+}$ \\
& $\mathrm{C}$ & $60 \pm 6$ & $66 \pm 5$ & $153 \pm 3^{+}$ & $81 \pm 5^{+}$ \\
$\mathrm{RER}$ & $\mathrm{NC}$ & $0.83 \pm 0.04$ & $0.88 \pm 0.03$ & $0.96 \pm 0.05^{+}$ & $0.83 \pm 0.03$ \\
& $\mathrm{C}$ & $0.82 \pm 0.03$ & $0.84 \pm 0.03$ & $0.91 \pm 0.04^{+}$ & $0.79 \pm 0.03$ \\
Glucose $\left(\mathrm{mg} \cdot \mathrm{dl} \mathrm{d}^{-1}\right)$ & $\mathrm{NC}$ & $94 \pm 4$ & $88 \pm 4$ & $86 \pm 3$ & $92 \pm 3$ \\
& $\mathrm{C}$ & $92 \pm 5$ & $90 \pm 4$ & $89 \pm 4$ & $95 \pm 4$
\end{tabular}

Note: Values are calculated as mean \pm SEM for duration of each condition. NC $(n=8)$ and $\mathrm{C}(n=8) .{ }^{*} \mathrm{NC}$ significantly different from $\mathrm{C}(p<0.05) ;{ }^{+}$Significantly different from rest $(p$ $<0.05)$. ${ }^{\text {a }} 50 \mathrm{~min}$ after entering heated room, $10 \mathrm{~min}$ before exercise, device not activated; b 55 min after entering heated room, before exercise with device activated for 5 min in C, not activated in NC. 


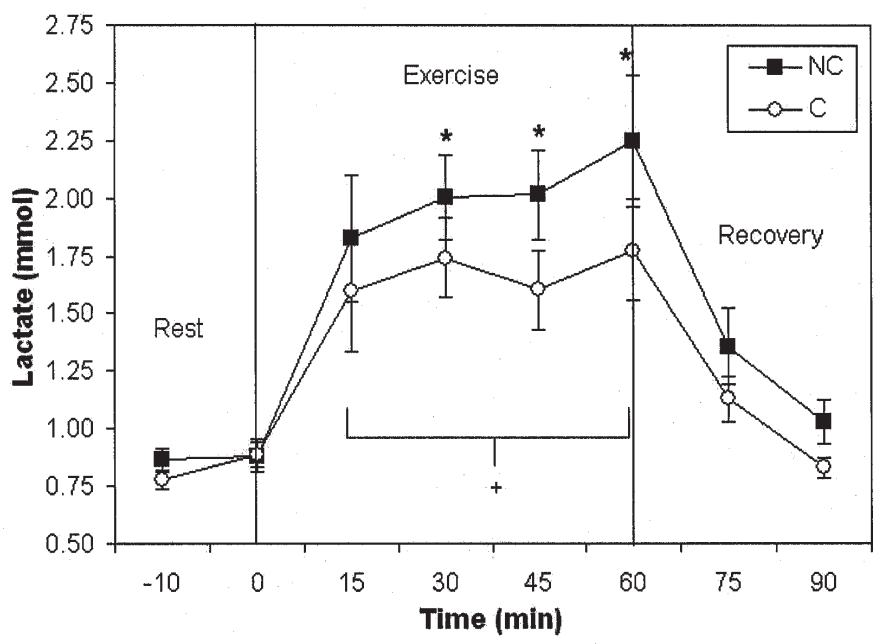

Figure 3. Blood lactate concentration during rest, exercise, and recovery (mean \pm $S E M) .{ }^{*} \mathrm{NC}$ significantly different from $\mathrm{C}$ during exercise $(p<0.01),{ }^{+}$Significantly different from rest $(p<0.05)$. $\mathrm{NC}=$ noncooled; $\mathrm{C}=$ cooled.

However, mean exercising $\dot{\mathrm{VO}}_{2}$ was higher when the subjects were not cooled, despite identical workloads $\left(\mathrm{NC}=2.7 \pm 0.1 \mathrm{~L} \cdot \mathrm{min}^{-1}\right.$ vs. $\mathrm{C}=2.4 \pm 0.1 \mathrm{~L} \cdot \mathrm{min}^{-1}, p<$ 0.05) (Table 1). Blood lactate concentration did not differ between trials during rest or recovery, but was higher during the last $30 \mathrm{~min}$ of exercise in the NC trial (2.25 mmol $\cdot \mathrm{L}^{-1}$ vs. $1.76 \mathrm{mmol} \cdot \mathrm{L}^{-1}, p<0.01$ ) (Figure 3 ).

Respiratory exchange ratio (RER) tended to be higher without cooling throughout exercise and recovery, but this difference was not statistically significant (Table 1). Blood glucose and heart rate (HR) did not differ during rest, exercise, or recovery between trials (Table 1). However, in both trials, HR increased from approximately 140 at $10 \mathrm{~min}$ of exercise to $160-165$ beats $\cdot \mathrm{min}^{-1}$ during the hour of exercise. Body mass changes were reduced by $12 \%$ in the $\mathrm{C}$ trial $(\mathrm{C}=0.97$ $\pm 0.20 \mathrm{~kg}$ vs. $\mathrm{NC}=1.10 \pm 0.30 \mathrm{~kg}$, n.s.). The estimated sweat rates based on the changes in body mass were 1.7 and 1.9 liters $\cdot \mathrm{hr}^{-1}$ for $\mathrm{C}$ and $\mathrm{NC}$, respectively.

\section{STUDY 2 (TIME-TRIAL TESTS)}

Cooling reduced the completion time of the $30-\mathrm{km}$ trial in all subjects (range $=1-$ $9 \mathrm{~min})$. Average completion time was $64.9 \pm 2.6 \mathrm{~min}$ for $\mathrm{NC}_{\mathrm{T}}$ and $60.9 \pm 2.0 \mathrm{~min}$ for $\mathrm{C}_{\mathrm{T}}$ (Figure 4 ), a mean improvement of $6 \pm 1 \%$ between trials $(p<0.01)$. No order effect was observed, as the 4 subjects who performed the $\mathrm{NC}_{\mathrm{T}}$ trial first improved by $6.5 \%$ while the 4 subjects who performed the $\mathrm{C}_{\mathrm{T}}$ trial first improved by $5.6 \%$. $\mathrm{T}_{\mathrm{TY}}$ did not differ at rest $\left(\mathrm{NC}_{\mathrm{T}}=36.8 \pm 0.1^{\circ} \mathrm{C} ; \mathrm{C}_{\mathrm{T}}=36.9 \pm 0.1^{\circ} \mathrm{C}\right)$, and although not significantly different during exercise, $\mathrm{T}_{\mathrm{TY}}$ appeared to be increasing more rapidly at the end of exercise in the noncooled trial (Figure 5). Peak exerciseinduced $\mathrm{T}_{\mathrm{TY}}$ increases were reduced from $1.6 \pm 0.1^{\circ} \mathrm{C}$ to $1.2 \pm 0.2^{\circ} \mathrm{C}$ above baseline 


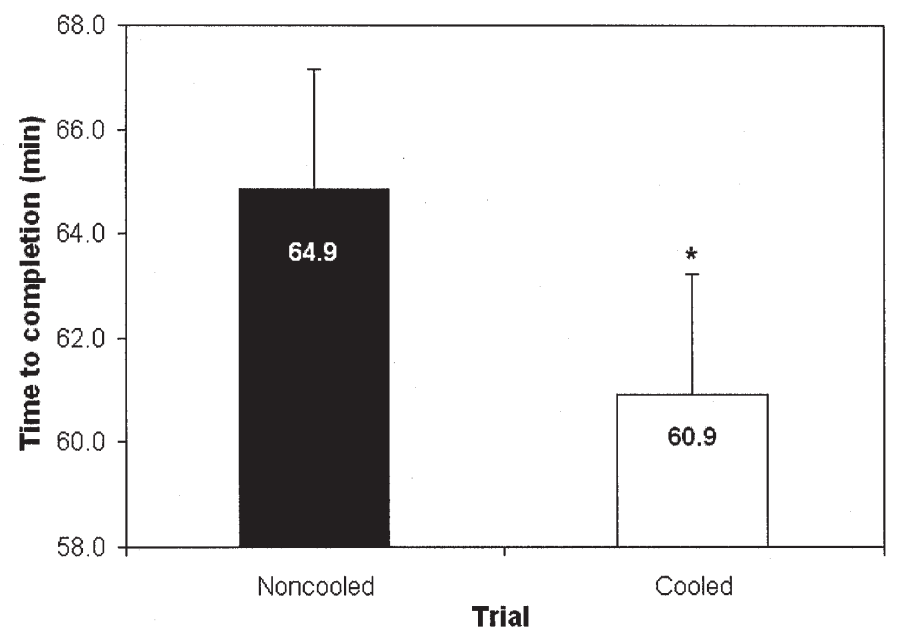

Figure 4. Time to completion of 30 -km cycling time-trial (mean $\pm S E M) .{ }^{*} \mathrm{C}_{\mathrm{T}}$ significantly different from $\mathrm{NC}_{\mathrm{T}}(p<0.01)$. $\mathrm{NC}_{\mathrm{T}}=$ noncooled; $\mathrm{C}_{\mathrm{T}}=$ cooled.

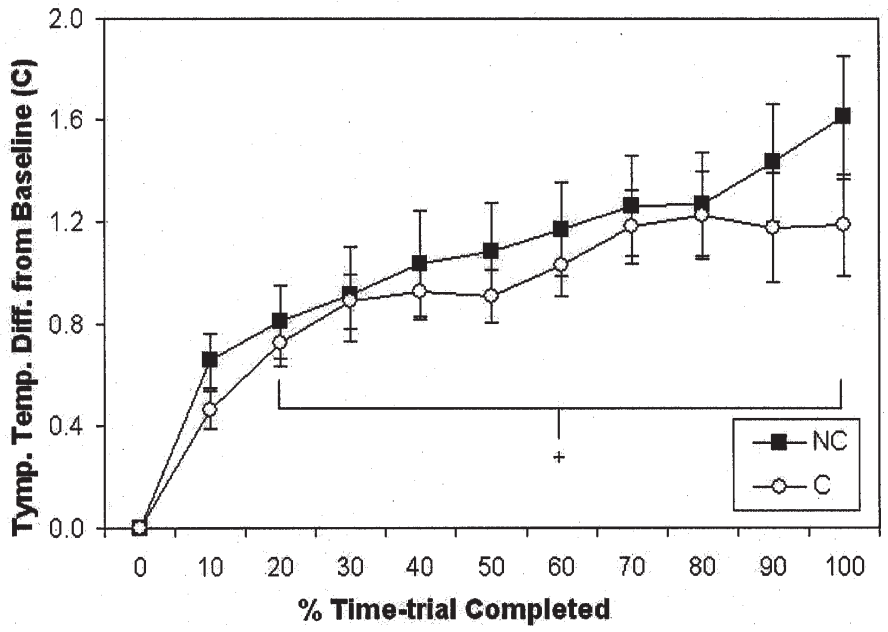

Figure 5. Tympanic temperature $\left(\mathrm{T}_{\mathrm{TY}}\right)$ difference from baseline over percent time-trial completed (mean $\pm S E M) .{ }^{+}$Significantly different from rest $(p<0.05)$. $\mathrm{NC}_{\mathrm{T}}=$ noncooled; $\mathrm{C}_{\mathrm{T}}=$ cooled. 
during cooled trials, but this difference was not significant (Figure 5). The largest temperature separation in $\mathrm{T}_{\mathrm{TY}}$ occurred during the last $20 \%$ of the time trial when the workload was $14 \pm 5 \%$ higher in the cooled trial $(173 \pm 11$ vs. $150 \pm 10 \mathrm{~W}$, n.s., $p=0.06)$.

No significant differences were observed in skin temperatures or heart rates between time-trial tests. $\mathrm{T}_{\mathrm{B}}$ and $\mathrm{T}_{\mathrm{F}}$ tended to fall at 10 and $40 \mathrm{~min}$ of exercise, respectively, in the cooled trial but not in the noncooled trial, and afterward the skin temperatures increased over time in both trials. During exercise, $\mathrm{T}_{\mathrm{F}}$ demonstrated a peak increase of $1.0 \pm 0.5^{\circ} \mathrm{C}$ without cooling, but only $0.73 \pm 0.4^{\circ} \mathrm{C}$ with cooling (Figure 6a). Similarly, $\mathrm{T}_{\mathrm{B}}$ increased by $1.2 \pm 0.5^{\circ} \mathrm{C}$ and $0.6 \pm 0.3{ }^{\circ} \mathrm{C}$ in $\mathrm{NC}_{\mathrm{T}}$ and $\mathrm{C}_{\mathrm{T}}$, respectively (Figure $6 \mathrm{~b}$ ). $\mathrm{HR}$ was similar between trials $\left(\mathrm{NC}_{\mathrm{T}}=159 \pm\right.$ 8 beats $\cdot \mathrm{min}^{-1} ; \mathrm{C}_{\mathrm{T}}=161 \pm 9$ beats $\cdot \mathrm{min}^{-1}$ ) despite higher workloads and faster completion times in the cooled trial.

\section{Discussion}

The main findings of this study were: (a) The hand-cooling device attenuated exercise-induced increases in $\mathrm{T}_{\mathrm{TY}}$, $\dot{\mathrm{VO}}_{2}$, and lactate during submaximal cycling exercise in the heat, and (b) cooling decreased the completion time of a 30-km time trial for all subjects. These results are consistent with improvements reported in preexercise cooling experiments (Booth et al., 1997; Gonzalez-Alonso et al., 1999; Hessemer et al., 1984; Lee and Haymes, 1995). However, whereas benefits from precooling techniques tend to decrease as the duration of exercise increases, the cooling technique used in the current study had its greatest impact on tympanic temperature toward the end of exercise when heat storage and accumulation was the greatest.

\section{TYMPANIC TEMPERATURE}

Elevated core temperature can be a limiting factor during exercise, and the body's heat storage capacity is directly related to exercise intensity, body size, and environmental conditions (Febbraio, 2000). Nielsen (1996) has shown that the rate of rise in core temperature is increased in hot environments, and that in the heat, the limit for body heat storage is reached faster for a given exercise intensity. In our study, heat storage was reduced via use of the hand-cooling device, as evidenced by the suppression of the rise in $\mathrm{T}_{\mathrm{TY}}$ by $0.6^{\circ} \mathrm{C}(p<0.01)$ in Study 1 during the cooled vs. noncooled trials. Similar reductions in core temperature achieved in precooling studies $\left(0.5-0.8^{\circ} \mathrm{C}\right)$ have resulted in significant short-term performance improvements such as increased sustained workloads and delayed times to exhaustion (Hessemer et al., 1984; Lee and Haymes, 1995; Olschewski and Bruck, 1988; Schmidt and Bruck, 1981).

Attainment of a critically high core temperature of approximately $40{ }^{\circ} \mathrm{C}$ has been shown to result in the voluntary termination of exercise (Gonzalez-Alonso et al., 1999; Nielsen et al., 1993). However, a reduction in power output during exercise performance tests (Tatterson et al., 2000) and changes in metabolic parameters associated with submaximal exercise (Hargreaves et al., 1996a; Jentjens et al., 2002) have been reported with core temperatures well below $40^{\circ} \mathrm{C}$. Therefore, although the current study did not test subjects to exhaustion, previous data sug- 

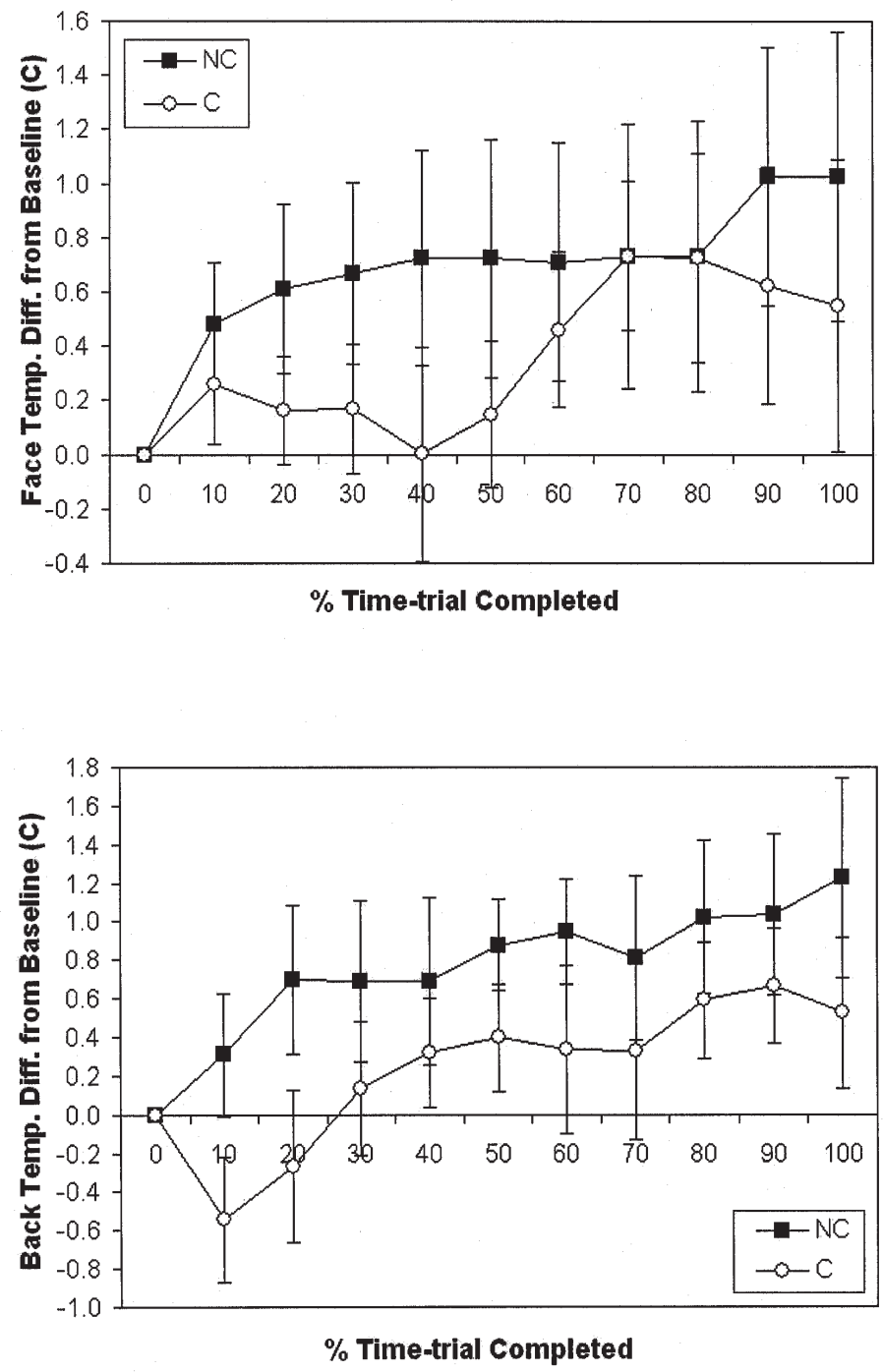

Figure 6. Difference from baseline over percent time-trial completed (mean $\pm S E M$ ). (a) Face temperature $\left(\mathrm{T}_{\mathrm{F}}\right)$; (b) Back temperature $\left(\mathrm{T}_{\mathrm{B}}\right) . \mathrm{NC}_{\mathrm{T}}=$ noncooled; $\mathrm{C}_{\mathrm{T}}=$ cooled. 
gests that the device could still be effective at reducing fatigue and increasing power output at moderately high tympanic temperatures.

\section{STUDY 1 (FIXED-WORKLOAD TESTS)}

Cardiovascular and Metabolic Responses. A lower $\mathrm{T}_{\mathrm{TY}}$ during exercise in the cooled trial was associated with a reduced metabolic cost $\left(\mathrm{V}_{2}\right)$ for a given workload, but not a lower heart rate. These results conflict with previous work demonstrating that exercise in the heat does not elevate $\mathrm{VO}_{2}$, but it does significantly increase heart rate (Febbraio, 1994b; Hargreaves et al., 1996a). Febbraio et al. (1994a) has even shown a significant reduction of $\dot{\mathrm{VO}}_{2}$ in the heat in endurance trained cyclists. They explain their findings by noting a possible reduced $\mathrm{O}_{2}$ supply to the working muscles in the heat, but due to lack of direct leg $\mathrm{VO}_{2}$ measurements they made no definite conclusions.

Our results do not support the interpretations in the literature regarding the effects of heat on $\dot{\mathrm{VO}}_{2}$. A small reduction in $\dot{\mathrm{VO}}_{2}$ with cooling might be expected if heart rate and ventilation were reduced due to improved stroke volume and reduced blood acidosis, respectively. Lower acidosis could result from a reversal with cooling of the documented heat-induced increase in carbohydrate utilization (Febbraio et al., 1994a; Hargreaves et al., 1996a). A reduction in rapid CHO use would decrease the dissociation of $\mathrm{H}^{+}$during fast glycolysis and improve metabolic homeostasis in the cooled trial. In addition, tighter coupling of oxidative phosphorylation, due to a reduction in muscle temperature or better ion clearance in the cooled trial, could result in increased respiratory capacity and ATP generation for a given $\dot{\mathrm{VO}}_{2}$ (Brooks et al., 1971; Carafoli and Rossi, 1971). However, such reasoning does not explain why our data differs from that of others regarding $\dot{\mathrm{V}} \mathrm{O}_{2}$ response in the heat, nor why we found no differences in heart rate. It was expected that lowering core temperature would reduce dehydration and increase the blood volume available for central circulation, thereby increasing stroke volume and decreasing heart rate. However, we observed only nonsignificant differences in mean exercising heart rate of approximately 4 beats $\cdot \mathrm{min}^{-1}$ between trials.

It is possible that differences in heart rate may have been minimized by the scheduled hydration included in our protocol. According to the dehydration-induced model of CV drift proposed by Coyle and Gonzalez-Alonso (2001), dehydration plays a central role in increasing heart rate by causing a reduction in stroke volume via hypovolemia and hyperthermia without an associated vasodilation of peripheral vessels. By requiring subjects to consume $250 \mathrm{ml}$ of water before exercise and $750 \mathrm{ml}$ during exercise, we may have reduced differences in dehydrationinduced increases in heart rate between trials. Hargreaves et al. (1996b) demonstrated decreases in heart rate of trained men ingesting sufficient fluid during exercise to prevent loss in body mass. However, our subjects did experience fluid losses $(\sim 1 \mathrm{~kg})$ despite the hydration protocol, and we observed a corresponding drift in heart rate from approximately 140 to $160-165$ beats $\cdot \mathrm{min}^{-1}$ during exercise in both trials. It is likely that the moderate discrepancies in internal $\mathrm{T}_{\mathrm{TY}}$ in the presence of similar environmental conditions in the current study elicit different cardiovascular responses than the larger internal core and environmental temperature separations experienced by subjects in previous studies comparing exercise in ambient 
$\left(20^{\circ} \mathrm{C}\right)$ vs. heated conditions $\left(40^{\circ} \mathrm{C}\right)$ (Febbraio et al., 1994a; 1994b; Hargreaves et al., 1996a).

Studies have shown that exercise in the heat causes an increase in respiratory exchange ratio (RER), indicating an elevated reliance on $\mathrm{CHO}$ over fat for energy (Febbraio et al., 1994a; Hargreaves et al., 1996a). Increased CHO oxidation has been associated with accelerated depletion of glycogen stores in the heat (Febbraio et al., 1996) and premature fatigue due to limited substrate availability in ambient environments (Febbraio et al., 1999b). We found that RER tended to be higher in NC vs. C during exercise, although at least part of the separation in values during exercise appears to have resulted from differences during rest. Even so, mean exercise values of $0.96 \pm 0.05$ for $\mathrm{NC}$ and $0.91 \pm 0.04$ for $\mathrm{C}$ achieved during exercise represent approximately a $25 \%$ reduction in $\mathrm{CHO}$ use with cooling at the end of exercise.

Such reductions in $\mathrm{CHO}$ utilization are consistent with those previously reporting a $25 \%$ reduction in muscle glycogenolysis during exercise in cool vs. heated conditions (Febbraio et al., 1994b; Jentjens et al., 2002). In this study, lactate concentrations during exercise were also lower in the cooled vs. noncooled trial, which could be attributed to decreased glycolytic flux or increased clearance by muscle or gluconeogenic tissues resulting from changes in blood flow distribution. Others have also observed lower lactate concentrations during exercise in ambient vs. heated conditions (Febbraio et al., 1994a; 1994b; Hargreaves et al., 1996a).

\section{STUDY 2 (TIME-TRIAL TESTS)}

All subjects completed the $30-\mathrm{km}$ time-trial in significantly less time with cooling. The study design was randomized and counterbalanced, and there was no order/ learning effect on the improvements observed (6.5\% vs. 5.6\% improvement for those who performed the noncooled trial first vs. second, respectively). The 2$15 \%$ individual performance improvements observed with cooling may have been due to the suppression of exercise-induced increases in thermoregulatory and metabolic parameters such as $\mathrm{T}_{\mathrm{TY}}, \dot{\mathrm{VO}}_{2}$, and lactate described in Study 1. Such reasoning is supported by the observation that during the last $20 \%$ of the time trial, cooled subjects were able to cycle at a $14 \pm 5 \%$ higher workload $(p=0.06)$ while maintaining the same heart rate and $\mathrm{T}_{\mathrm{TY}}$ as in the noncooled trial.

These results are consistent with those of Tatterson et al. (2000), who showed that trained cyclists significantly reduced their work output by $6.5 \%$ in a heated $\left(32{ }^{\circ} \mathrm{C}\right)$ compared to an ambient $\left(23^{\circ} \mathrm{C}\right)$ environment to maintain identical core temperatures. In the Tattereson et al. study, the reduction in workload occurred within 15 min of the start of exercise (when core temperature had risen less than 1 ${ }^{\circ} \mathrm{C}$ ), and continued throughout the trial. Therefore, it appears that subjects who are allowed to choose their workloads under different environmental or external cooling conditions will choose an intensity that results in equivalent core temperatures for them even before core temperature approaches the critical value of $40^{\circ} \mathrm{C}$.

\section{$\mathrm{T}_{\mathrm{F}}$ AND $\mathrm{T}_{\mathrm{B}}$ CONSIDERATIONS}

Although $\mathrm{T}_{\mathrm{F}}$ and $\mathrm{T}_{\mathrm{B}}$ tended to be lower in the cooled trials in both parts of the study, these results are difficult to interpret because the exact relationship between 
skin temperature $\left(\mathrm{T}_{\mathrm{sk}}\right)$ and core temperature is uncertain. Gonzalez-Alonso et al. (1999) have found that lowering core temperature significantly lowers $T_{\text {sk }}$, but other study results have shown no significant correlations between the two (Bolster et al., 1999). Precooling techniques such as water immersion and cold air acclimation directly lower core temperature through skin contact, thus making it unclear whether the reduced core temperature lowers $\mathrm{T}_{\mathrm{sk}}$ or vice versa. Lee and Haymes (1995) found that precooling the skin attenuated the rise in rectal temperature during exercise in the heat. Therefore, low $\mathrm{T}_{\mathrm{sk}}$ could indicate a reduced core temperature due to the lack of internal heat being shunted to the surface of the body. However, low $\mathrm{T}_{\mathrm{sk}}$ could also indicate an elevated core temperature causing cooler $\mathrm{T}_{\mathrm{sk}}$ via increased sweating response and evaporative cooling. To examine possible sweat rate influences on $\mathrm{T}_{\mathrm{sk}}$, we measured changes in body mass during exercise in Study 1. Although subjects drank equal amounts of water before and during tests $(1,000 \mathrm{ml}$ total), they experienced a $12 \%$ greater water loss in the noncooled trial. Therefore it is more likely that the trend for lower values of $\mathrm{T}_{\mathrm{F}}$ and $\mathrm{T}_{\mathrm{B}}$ in $\mathrm{C}$ was a reflection of lower core temperature rather than an increased sweat rate.

\section{METHODOLOGICAL CONSIDERATIONS}

A possible limitation to this study was the use of $\mathrm{T}_{\mathrm{TY}}$ instead of rectal or esophageal temperature. Results from Sawka et al. (1989) suggest that core temperature measured in a specific body region may vary significantly compared to another region. Thus, measuring core temperature through the tympanic membrane vs. the rectum and esophagus may produce different results. Studies suggest that $\mathrm{T}_{\mathrm{TY}}$ may underestimate core temperature by $0.3-0.6^{\circ} \mathrm{C}$ relative to esophageal or rectal temperature (Jensen et al., 2000; Roth et al., 1996; Shiraki et al., 1986; Yeo and Scarbough, 1996). However, Newsham et al. (2002) have also shown a strong correlation between $\mathrm{T}_{\mathrm{TY}}$ and rectal temperature.

In this study, $\mathrm{T}_{\mathrm{TY}}$ was consistently measured in the left ear, and no fan or airflow was permitted during any of the tests. Subjects inserted the tympanic probes as far as possible until contact was made with the tympanic membrane. A small cotton ball attached to the end of the probe also ensured that there was no external heat input from the environment. Under these controlled conditions, $\mathrm{T}_{\mathrm{TY}}$ should provide a reasonable estimate of core temperature. As stated in the Methods section, ongoing work in our lab using similar subjects and identical exercise testing procedures has shown a strong correlation between $\mathrm{T}_{\mathrm{TY}}$ and esophageal temperature $(r=0.99)$, with $\mathrm{T}_{\mathrm{TY}}$ consistently lower by $\sim 0.5{ }^{\circ} \mathrm{C}$ but with identical rises above baseline between the two measurements.

A second consideration is that there was no true placebo control in this study. Although subjects performed all testing with their hands in the device, they were aware that the suction was on and that the plate felt cooler when the device was activated. To minimize the potential confound, subjects were tested in a partially naïve state, meaning they were given no information regarding previous or expected results. It could be argued that performance in the time-trial test was impacted by the placebo effect, but it is unlikely that the differences observed in the set-workload protocol would have resulted from such an effect. The observed changes in $\mathrm{T}_{\mathrm{TY}}$, lactate, and $\dot{\mathrm{VO}}_{2}$ would have been difficult for the subjects to alter simply by knowing that the device was activated. Independent of the placebo ef- 
fects, having subjects place their hand in the device for both trials was important for eliminating changes in body position that could have impacted the findings (e.g., heart rate).

Finally, as with any intervention, some subjects benefited more from handcooling than others. Part of the variation in response may be due to individual differences in the threshold for local cold-induced vasoconstriction of the AVAs in the hand. In using the device, there must be a balance between establishing the maximum temperature gradient to extract as much heat as possible, while avoiding vasoconstriction in response to a local cold stimulus. In the current study, the greatest difference in $\mathrm{T}_{\mathrm{TY}}$ between treatments appeared toward the end of exercise (this was likely a result of differing rates of heat storage between trials over the course of the exercise bout). However, we also hypothesize that the device may function better toward the end of exercise because the increase in core temperature may lower the local vasoconstriction response threshold of the AVAs in "nonresponders." Livingstone et al. (1989) demonstrated that immersion of the hand in cold water as low as $10^{\circ} \mathrm{C}$ during exercise recovery was more effective at lowering core temperature when the preceding work output and body heat storage was higher.

Although previous studies using hand immersion postexercise also suggest that colder water temperatures as low as $10^{\circ} \mathrm{C}$ can extract more heat than water at 20 and $30{ }^{\circ} \mathrm{C}$ (House et al., 1997; Livingstone et al., 1989), manufacturers of the hand-cooling device suggest that the $22^{\circ} \mathrm{C}$ temperature used in the current study was optimal for reducing the occurrence of nonresponders both at rest and during exercise. In the future, the addition of a heat-removal feedback system based on the temperature differential between water in vs. out would augment heat extraction and calculation of heat removal by enabling the adjustment of plate temperature to the ideal range in real time for each individual.

\section{Conclusion}

In summary, we found that heat extraction through the palm of the hand could attenuate the rise in $\mathrm{T}_{\mathrm{TY}}, \dot{\mathrm{VO}_{2}}$, and lactate during submaximal exercise in the heat. The benefits of hand-cooling on these thermoregulatory and metabolic responses may have contributed to the ability of the subjects to decrease the time to complete a set amount of work on a cycle ergometer. Taken together, the two studies we conducted suggest that heat extraction through the hand may provide a means of improving cycling performance. However, future research is needed to clearly identify the underlying mechanism supporting the efficacy of the device and to determine whether the device can be adapted for use in a field setting.

\section{Acknowledgments}

We are grateful to the subjects for their participation, and to the nursing staff in the Clinical Studies Unit at the Veterans Affairs Palo Alto Health Care System for their assistance with subject testing. Results from this study do not constitute endorsement of the hand-cooling device by the authors or this journal. This study was supported by the Dept. of Veterans Affairs, Gatorade Sports Science Institute, and Stanford University Undergraduate Research Opportunities Office. 


\section{References}

Bolster, D.R., Trappe, S.W., Short, K.R., Scheffield-Moore, M., Parcell, A.C., Schulze, K.M., and Costill, D.J. (1999). Effects of precooling on thermoregulation during subsequent exercise. Med. Sci. Sports Exerc. 31: 251-257.

Booth, J., Marino, F., and Ward, J.J. (1997). Improved running performance in hot humid conditions following whole body precooling. Med. Sci. Sports Exerc. 29: 943-949.

Brooks, G.A., Hittelman, K.J., Faulkner, J.A., and Beyer, R.E. (1971). Temperature, skeletal muscle mitochondrial functions, and oxygen debt. Am. J. Physiol. 220: 10531059.

Carafoli, E., and Rossi, C.S. (1971). Calcium transport in mitochondria. Adv. Cytopharmacol. 1: 209-227.

Coyle, E.F., and Gonzalez-Alonso, J. (2001). Cardiovascular drift during prolonged exercise: New perspectives. Exerc. Sport Sci. Rev. 29: 88-92.

Febbraio, M.A. (1999a). Temperature, muscle metabolism and performance. In: D.L. Lamb and R. Murray (Eds.), The Metabolic Bases of Performance in Sport and Exercise, pp. 315-353. Carmel, IN: Cooper Publ. Group.

Febbraio, M.A. (2000). Does muscle function and metabolism affect exercise performance in the heat? Exerc. Sport Sci. Rev. 28: 171-176.

Febbraio, M.A., and Dancey, J. (1999b). Skeletal muscle energy metabolism during prolonged, fatiguing exercise. J. Appl. Physiol. 87: 2341-2347.

Febbraio, M.A., Snow, R.J., Hargreaves, M., Stathis, C.G., Martin, I.K., and Carey, M.F. (1994b). Muscle metabolism during exercise and heat stress in trained men: Effect of acclimation. J. Appl. Physiol. 76: 589-597.

Febbraio, M.A., Snow, R.J., Stathis, C.G., Hargreaves, M., and Carey, M.F. (1994a). Effect of heat stress on muscle energy metabolism during exercise. J. Appl. Physiol. 77: 2827-2831.

Febbraio, M.A., Snow, R.J., Stathis, C.G., Hargreaves, M., and Carey, M.F. (1996). Blunting the rise in body temperature reduces muscle glycogenolysis during exercise in humans. Exp. Physiol. 81: 685-693.

Gonzalez-Alonso, J., Teller, C., Andersen, S.L., Jensen, F.B., Hyldig, T., and Nielsen, B. (1999). Influence of body temperature on the development of fatigue during prolonged exercise in the heat. J. Appl. Physiol. 86: 1032-1039.

Grahn, D., Brock-Utne, J.G., Watenpaugh, D.E., and Heller, H.C. (1998). Recovery from mild hypothermia can be accelerated by mechanically distending blood vessels in the hand. J. Appl. Physiol. 85: 1643-1648.

Hagobian, T.A., Jacobs, K.A., Kiratli, B.J., and Friedlander, A.L. (2004). Foot cooling reduces exercise-induced hyperthermia in men with spinal cord injury. Med. Sci. Sports Exerc. 36: 411-417.

Hargreaves, M., Angus, D., Howlett, K., Conus, N.M., and Febbraio, M. (1996a). Effect of heat stress on glucose kinetics during exercise. J. Appl. Physiol. 81: 1594-1597.

Hargreaves, M., Dillo, P., Angus, D., and Febbraio, M. (1996b). Effect of fluid ingestion on muscle metabolism during prolonged exercise. J. Appl. Physiol. 80: 363-366.

Hessemer, V., Langusch, D., Bruck, L.K., Bodeker, R.H., and Breidenbach, T. (1984). Effect of slightly lowered body temperatures on endurance performance in humans. J. Appl. Physiol. 57: 1731-1737.

House, J.R., Holmes, C., and Allsopp, A.J. (1997). Prevention of heat strain by immersing the hands and forearms in water. J. R. Nav. Med. Serv. 83: 26-30. 
Jensen, B.N., Jensen, F.S., Madsen, S.N., and Lossl, K. (2000). Accuracy of digital tympanic, oral, axillary, and rectal thermometers compared with standard rectal mercury thermometers. Eur. J. Surg. 166: 848-851.

Jentjens, R.L., Wagenmakers, A.J., and Jeukendrup, A.E. (2002). Heat stress increases muscle glycogen use but reduces the oxidation of ingested carbohydrates during exercise. J. Appl. Physiol. 92: 1562-1572.

Lee, D.T., and Haymes, E.M. (1995). Exercise duration and thermoregulatory responses after whole body precooling. J. Appl. Physiol. 79: 1971-1976.

Livingstone, S.D., Nolan, R.W., and Cattroll, S.W. (1989). Heat loss caused by immersing the hands in water. Aviat. Space Environ. Med. 60: 1166-1171.

Mao, I.F., Chen, M.L., and Ko, Y.C. (2001). Electrolyte loss in sweat and iodine deficiency in a hot environment. Arch. Environ. Health 56: 271-277.

Newsham, K.R., Saunders, J.E., and Nordin, E.S. (2002). Comparison of rectal and tympanic thermometry during exercise. South. Med. J. 95: 804-810.

Nielsen, B. (1996). Olympics in Atlanta: A fight against physics. Med. Sci. Sports Exerc. 28: 665-668.

Nielsen, B., Hales, J.R., Strange, S., Christensen, N.J., Warberg, J., and Saltin, B. (1993). Human circulatory and thermoregulatory adaptations with heat acclimation and exercise in a hot, dry environment. J. Physiol. 460: 467-485.

Olschewski, H., and Bruck, K. (1988). Thermoregulatory, cardiovascular, and muscular factors related to exercise after precooling. J. Appl. Physiol. 64: 803-811.

Roth, R.N., Verdile, V.P., Grollman, L.J., and Stone, D.A. (1996). Agreement between rectal and tympanic membrane temperatures in marathon runners. Ann. Emerg. Med. 28: 414-417.

Sawka, M.N., Latzka, W.A., and Pandolf, K.B. (1989). Temperature regulation during upper body exercise: Able-bodied and spinal cord injured. Med. Sci. Sports Exerc. 21: S132-S140.

Schmidt, V., and Bruck, K. (1981). Effect of a precooling maneuver on body temperature and exercise performance. J. Appl. Physiol. 50: 772-778.

Shiraki, K., Konda, N., and Sagawa, S. (1986). Esophageal and tympanic temperature responses to core blood temperature changes during hyperthermia. J. Appl. Physiol. 61: 98-102.

Tatterson, A.J., Hahn, A.G., Martin, D.T., and Febbraio, M.A. (2000). Effects of heat stress on physiological responses and exercise performance in elite cyclists. J. Sci. Med. Sport 3: 186-193.

Yeo, S., and Scarbough, M. (1996). Exercise-induced hyperthermia may prevent accurate core temperature measurement by tympanic membrane thermometer. J. Nurs. Meas. 4: $143-151$.

Received April 16, 2004; accepted in final form July 23, 2004. 